\title{
Fluxo de biomassa em capim-tanzânia sob lotação rotativa com quatro níveis de suplementação concentrada ${ }^{1}$
}

\section{Roberto Cláudio Fernandes Franco Pompeu², Magno José Duarte Cândido ${ }^{3}$, José Neuman Miranda Neiva $^{4}$, Marcos Cláudio Pinheiro Rogério ${ }^{5}$, Yuri Ida Benevides ${ }^{6}$, Bruno César Moura de Oliveira $^{7}$}

\author{
${ }^{1}$ Pesquisa financiada com recursos do convênio UFC - Banco do Nordeste/FUNDECI. \\ 2 Doutorando em Zootecnia da Universidade Federal do Ceará. Brasil. Av. Mister Hull, s/n, Fortaleza, CE, CEP: 60970-355. \\ 3 Departamento de Zootecnia da Universidade Federal do Ceará. \\ ${ }^{4}$ Departamento de Medicina Veterinária e Zootecnia da Universidade Federal de Tocantins. \\ ${ }^{5}$ Departamento de Zootecnia da Universidade Estadual do Vale do Acaraú. \\ ${ }^{6}$ Doutoranda em Zootecnia da Universidade Federal de Minas Gerais. \\ 7 Graduando em Engenharia Agronômica da Universidade Federal do Ceará. Brasil.
}

RESUMO - Avaliou-se o fluxo de biomassa em capim-tanzânia sob lotação rotativa com quatro níveis de suplementação concentrada, com período de ocupação de três dias e descanso de 21 dias, em delineamento de parcelas subdivididas, de modo que as parcelas foram os níveis de suplementação $(0,0 ; 0,6 ; 1,2$ e 1,8\% do PV) e as subparcelas, os ciclos de pastejo (quatro), com três repetições (piquetes amostrais). Não houve efeito dos níveis de suplementação e dos ciclos de pastejo sobre a relação entre as taxas de lâmina foliar (TAlF) das folhas 1 e 2 recentemente expandidas, com média de 0,69. A suplementação e os ciclos de pastejo tiveram efeito quadrático sobre a taxa de alongamento foliar, cujas estimativas foram de 5,04; 4,95 (ponto de mínimo estimado) e 5,7 cm/perfilho dia nos níveis de 0,0; 0,46 e 1,8\% de suplementação, respectivamente. A taxa de alongamento das hastes e a altura do pseudocolmo não foram afetadas pelos níveis de suplementação. As taxas de senescência foliar anterior, posterior e total não foram afetadas pelos níveis de suplementação nem pelos ciclos de pastejo. Não houve efeito dos níveis de suplementação nem dos ciclos de pastejo sobre o filocrono. A taxa de crescimento da cultura e a taxa de acúmulo da cultura não foram afetadas pelos níveis de suplementação nem pelos ciclos de pastejo. O índice de área foliar residual foi estimado em 2,00 e de 2,72 nos níveis de suplementação de 0,0 e 1,8\% PV. Não houve diferença na densidade populacional de perfilhos entre os níveis de suplementação, porém, entre ciclos, observou-se que o ciclo 4 foi superior ao 2 e semelhante aos demais. Os componentes do fluxo de biomassa do capim-tanzânia são pouco afetados pelos níveis de suplementação.

Palavras-chave: densidade populacional de perfilhos, índice de área foliar, Panicum maximum, taxa de alongamento das hastes, taxa de alongamento foliar, taxa de senescência foliar

\section{Biomass flow of tanzania grass under intermittent stocking with four concentrate supplementation levels}

\begin{abstract}
The biomass flow of Panicum maximum cv. Tanzania under intermittent stocking with four concentrate supplementation levels, with three grazing periods and 21 rest periods was evaluated. A split plot design, with supplementation level (0.0, 0.6, 1.2 and 1.8\% of live weight) and grazing cycles as sub-parcels, with three replicates (paddocks) by treatment was used. There was no effect between supplementation levels and grazing cycles on the leaves 1 and 2 TAlF ratio, averaging 0.69. There was a square effect of the supplementation level on the leaf elongation rate, estimating 5.04, 4.95 (estimated minimum point) and $5.70 \mathrm{~cm} /$ tiller $\times$ day to the levels of $0.0,0.46$ and $1.8 \% \mathrm{LW}$, respectively. No effect of the supplementation levels on the culm elongation rate and culm height was observed. The supplementation levels and grazing cycles did not affect the senescence rate of leaves remaining after grazing, of the new emerged leaves, the total senescence rate. No effect of the supplementation levels and grazing cycles on the phylochron was observed. There was no effect of the supplementation levels and grazing cycles on the herbage growth and herbage accumulation rates. A residual leaf area index of 2.00 and 2.72 was estimated for supplementation levels of 0.0 and $1.8 \% \mathrm{LW}$. No effects of the supplementation levels on the tiller population density were observed. In relation to the cycles, cycle 4 was higher than cycle 2 and similar to the others. The biomass flows of tanzania grass are little affected by the supplementation levels.
\end{abstract}

Key Words: culm elongation rate, leaf area index, leaf elongation rate, leaf senescence rate, Panicum maximum, tiller population density 


\section{Introdução}

A produtividade das gramíneas forrageiras depende da contínua emissão de folhas e perfilhos, processo importante para a restauração da área foliar após o corte ou pastejo e que garante perenidade à pastagem. Os processos de formação e desenvolvimento de folhas são fundamentais para o crescimento vegetal, pois são responsáveis pela fotossíntese, ponto de partida para a formação de novos tecidos (Gomide \& Gomide, 2000).

O crescimento das plantas está condicionado à obtenção de energia proveniente da radiação solar, por meio de sua interceptação e utilização no processo de fotossíntese. O tamanho da superfície de interceptação, representado pela área foliar, depende de características inerentes ao genótipo (Nabinger \& Pontes, 2001), embora estas características possam ser afetadas por fatores ambientais, como luz, temperatura, umidade e fertilidade do solo, e pelo manejo aplicado (intensidade e freqüência de corte ou pastejo), portanto, são importantes condicionadores da arquitetura do dossel. Assim, são necessários estudos detalhados sobre os mecanismos que afetam o crescimento e o desenvolvimento do pasto e de sua interação com o ambiente e manejo aplicado, a fim de se obter melhor aproveitamento da forragem produzida, com redução de perdas de forragem e garantia da perenidade do pasto.

Chapman \& Lemaire (1993) definiram a morfogênese de plantas como a dinâmica de geração e expansão da planta no espaço, que pode ser descrita como a taxa de aparecimento de novos órgãos (organogênese), a taxa de expansão e de senescência e a decomposição das plantas. Esses autores relataram ainda que, em pastagens onde são produzidas somente folhas, a morfogênese depende de três características principais: as taxas de aparecimento e de alongamento foliar e o período de vida das folhas. A combinação entre essas características determina as características estruturais do pasto.

No caso de gramíneas cespitosas do tipo $\mathrm{C}_{4}$, todavia, o alongamento das hastes ainda na fase vegetativa (Gomide, 2001; Cândido et al., 2005), apesar de aumentar o rendimento forrageiro, compromete a eficiência de pastejo, pois reduz a relação folha/colmo (Gomide, 2001; Alexandrino et al., 2005).

Na maioria dos trabalhos sobre suplementação a pasto, não é considerado o efeito da suplementação no ecossistema da pastagem. Assim, as pesquisas não têm dado ênfase à importância dos parâmetros morfológicos e fisiológicos nas gramíneas tropicais, portanto, é necessário conhecimento detalhado sobre a avaliação dos parâmetros morfogênicos da pastagem com diversos níveis de suplementação.

Na tentativa de se obter maior detalhamento da resposta da pastagem à suplementação, este estudo foi realizado com o objetivo de avaliar as respostas morfogênicas do dossel de Panicum maximum (Jacq.) cv. Tanzânia pastejado por ovinos sob lotação rotativa com quatro níveis de suplementação concentrada.

\section{Material e Métodos}

No Campo Avançado do Núcleo de Ensino e Estudos em Forragicultura-NEEF/DZ/CCA/UFC, foi conduzido o estudo do fluxo de biomassa de Panicum maximum cv. Tanzânia pastejado por ovinos com níveis crescentes de suplementação concentrada sob lotação rotativa e taxa de lotação variável. O Campo Avançado do NEEF está localizado na Fazenda Experimental Vale do Curu-FEVC/CCA/ UFC, em Pentecoste, Ceará, nas latitudes $3^{\circ} 40^{\prime}$ a $3^{\circ} 51^{\prime} 18^{\prime \prime}$ sul e longitudes $39^{\circ} 10^{\prime} 19^{\prime \prime}$ e $39^{\circ} 18^{\prime} 13$ oeste, em uma região cujo clima, segundo a classificação de Köeppen, é do tipo BSw'h', semiárido quente, com precipitação média anual de 806,5 mm, distribuída no período de janeiro a abril.

O solo da área experimental é classificado como Neossolo flúvico (solos aluviais) (Embrapa, 1999) de textura argilosa. Os dados de temperatura média, umidade relativa do ar, radiação e insolação do local no período experimental (setembro a dezembro de 2004) foram de $27,1^{\circ} \mathrm{C}, 65,5 \%$, $27,3 \mathrm{MJ} / \mathrm{m}^{2} \bullet$ dia e 9,3 horas, respectivamente.

A área experimental, de 1,5 ha, com topografia plana, dotada de sistema de irrigação do tipo aspersão fixa de baixa pressão e coberta com a gramínea Panicum maximum Jacq. cv. Tanzânia é manejada sob lotação rotativa desde 2003, sempre na estação seca de cada ano.

Foram avaliados quatro níveis de suplementação com ovinos pastejando Panicum maximum cv. Tanzânia sob lotação rotativa. Os níveis de suplementação corresponderam a 0,$0 ; 0,6 ; 1,2$ e 1,8\% do peso vivo (PV) dos ovinos por dia, considerando capacidade de consumo diário de matéria seca (MS) de 3,6\% PV, desta forma, no mais alto nível de suplementação, a proporção volumoso:concen-trado da dieta foi de 50:50. O dimensionamento dos piquetes foi feito de modo a garantir oferta de forragem de $7,2 \%$ do PV, considerando taxa de crescimento cultural (TCC) de $140 \mathrm{~kg}$ MS/ha•dia, conforme preconizado por Silva (2004).

Foram utilizados oito ovinos sem padrão racial definido (SPRD) por nível de suplementação, totalizando 32 animais-teste, distribuídos aleatoriamente entre os níveis de suplemento. O delineamento experimental utilizado foi 
o de parcelas subdivididas, de modo que os níveis de suplementação foram as parcelas e os ciclos de pastejo (quatro), as subparcelas, com três repetições (piquetes amostrais).

A área total para cada nível de suplementação, de $1.472 \mathrm{~m}^{2}$, foi dividida com cerca do tipo tela campestre em oito piquetes (local onde os animais de cada tratamento faziam rodízio), totalizando $183,6 \mathrm{~m}^{2}$ por piquete e $5.888 \mathrm{~m}^{2}$ de área experimental (32 piquetes - total dos quatro níveis de suplemento). O restante da área (aproximadamente $9.000 \mathrm{~m}^{2}$ ) foi utilizado como pasto de reserva para acondicionamento dos animais reguladores. Cada piquete foi provido de comedouros, bebedouros e sombrites de $8,0 \mathrm{~m}^{2}$, com $25 \%$ de transmitância de luz. O período de descanso (21 dias) correspondeu ao tempo necessário para a expansão de duas novas folhas por perfilho, conforme estimado por Silva (2004), e o período de pastejo foi de três dias. Os ovinos reguladores foram utilizados, quando necessário, para garantir o rebaixamento da vegetação para altura residual de 28,0 cm, correspondente a um índice de área foliar de 1,0 (Silva, 2004) ao final do terceiro dia de pastejo.

Para o condicionamento ao sistema de lotação rotativa, no início da pesquisa, foram colhidas três amostras de solo, que foram levadas ao Laboratório de Ciências do Solo (UFC) para determinação das características físico-químicas (Tabela 1). Antes do período experimental, foi feito o rebaixamento do capim a 20,0 cm de altura e, após a gramínea atingir $40,0 \mathrm{~cm}$ de altura, os animais foram colocados nos piquetes de seus respectivos níveis de suplemento para o rebaixamento sucessivo da vegetação a $28,0 \mathrm{~cm}$ de altura, com período de ocupação de três dias. Imediatamente depois de cada piquete atingir sua condição residual preconizada, foi feita adubação nitrogenada, fosfatada e com micronutrientes, conforme descrito pela Comissão de Fertilidade do Solo do Estado de Minas Gerais - CFSEME (1999), com uréia, superfosfato simples e FTE BR-12 como fonte desses nutrientes.

Durante o rodízio dos animais nos piquetes, foi feita adubação nitrogenada de cobertura em dose equivalente a $600 \mathrm{~kg}$ de N/ha•ano, ou 39,6 kg N/ha •ciclo [1,65 kg N/ha•dia $\times 24$ dias (ciclo de pastejo)], uma vez que o período de descanso era fixo. A adubação foi dividida em duas doses: a primeira logo após a saída dos animais e a segunda na metade do período de descanso, de modo que a área de reserva foi adubada de forma similar.

A irrigação na área foi realizada durante a noite, visando reduzir a perda de água, especialmente pelo efeito dos ventos, assim como possíveis perdas de nitrogênio por volatilização, em virtude das temperaturas elevadas durante o dia. A lâmina aplicada correspondeu a uma evapotranspiração da cultura de 7,97 mm/dia, com eficiência de aplicação de $70 \%$, de forma que a lâmina de água utilizada para o cálculo da eficiência de uso da água fosse de $11,4 \mathrm{~mm} / \mathrm{dia}(7,97 / 0,7)$, com o turno de rega de quatro dias no início e três dias do meio para o fim do experimento, em decorrência da redução na eficiência de irrigação.

Foram avaliados três piquetes por nível de suplementação, onde foram marcadas três touceiras após a saída dos animais, mudadas a cada novo ciclo de pastejo. Em cada uma das touceiras, três perfilhos foram identificados aleatoriamente com anéis coloridos de fio telefônico com fitas coloridas da mesma cor, atadas para facilitar sua localização. Nos perfilhos, foram registrados a cada seis dias o comprimento total e o da porção verde das lâminas não completamente mortas a partir da lígula da própria folha, quando expandida, ou da base da folha, quando emergente. A taxa de senescência foliar foi estimada pela diferença entre o comprimento total da lâmina foliar pelo comprimento de sua porção ainda verde; o valor encontrado foi dividido pelo número de dias em cada idade de rebrota. A estimativa do alongamento das hastes foi efetuada registrando-se a distância da lígula exposta mais alta em relação à base do colmo, seguindo sua inclinação, em leituras sucessivas ao longo do período de descanso.

Também foram determinados índices gravimétricos para alongamento de hastes e de folhas e para senescência foliar. Ao final de cada período de descanso, foram colhidos aproximadamente 30 perfilhos por piquete amostral, que foram levados ao laboratório e separados em hastes, lâminas foliares expandidas e lâminas foliares emergentes. Depois de registrado o comprimento total de cada uma, as frações foram secas em estufa de ventilação forçada a $65^{\circ} \mathrm{C}$, durante 72 horas, e pesadas para obtenção do índice de peso por unidade de comprimento da lâmina foliar emergente $(\alpha 1)$, da lâmina foliar expandida ( $\alpha 2)$ e das hastes $(\beta)$.

Tabela 1 - Resultados da análise de fertilidade do solo realizada em agosto de 2004

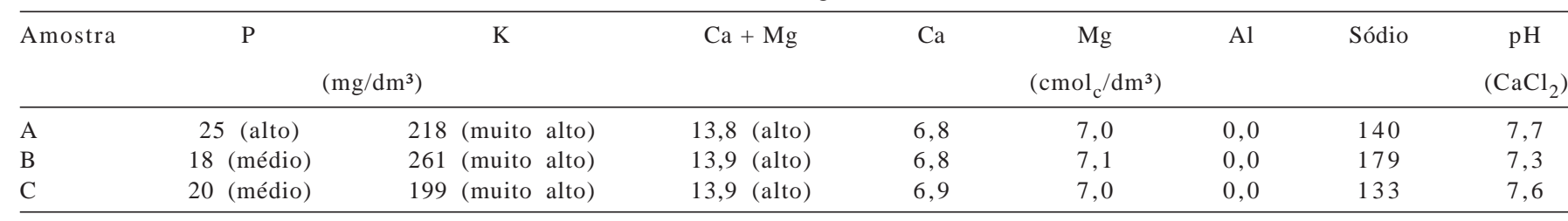


Assim, estimaram-se as taxas de crescimento (TCC) e de acúmulo (TAC) da cultura durante o período de descanso, a partir das taxas de alongamento (TAlF) e senescência (TSF) de lâmina foliar e da taxa de alongamento das hastes (TAlH) e da densidade populacional de perfilhos (DPP), conforme descrito por Davies (1993).

Objetivando maior detalhamento da resposta do dossel aos níveis de suplementação impostos, foram estimados os seguintes índices: razão TAlF1/TAlF2, referente à razão entre as taxas de alongamento de lâminas foliares da primeira e segunda folhas produzidas no início da rebrotação de cada perfilho. Sua estimativa enseja maior vigor do pasto para aqueles que apresentem uma razão TAlF1/TAlF2 mais próxima de 1,0, ou seja, quando o alongamento da primeira lâmina foliar não está comprometido em razão, por exemplo, da mobilização de reservas orgânicas, uma situação em que o crescimento reinicia-se mais lentamente; a altura do pseudocolmo (Pseud), que expressa a elevação das hastes durante o período de descanso; a taxa de senescência foliar anterior (TSFa) e a taxa de senescência foliar posterior (TSFp) referindo-se, respectivamente, à taxa de senescência de lâminas foliares formadas anteriormente ao pastejo e remanescentes deste e à taxa de senescência de lâminas foliares formadas posteriormente ao pastejo, ou seja, durante o período de descanso em apreço; a TST corresponde à taxa de senescência foliar total e representa a soma das senescências das folhas remanescentes do crescimento anterior ao último pastejo com a senescência das folhas formadas após o último pastejo, ou seja, no período de descanso (TST = TSFa + TSFp); o filocrono (FIL) expressa o tempo, em dias, necessário para a completa expansão de uma folha (Skinner \& Nelson, 1995), visualmente caracterizado pela exposição da lígula e calculado pelo inverso da taxa de aparecimento foliar (1/TApF), que é obtida pela divisão do número de folhas surgidas por perfilho, em cada idade da rebrota, pelo número de dias envolvidos; a densidade populacional de perfilhos (DPP) estimada cinco dias após os animais saírem dos piquetes, contando-se o número de touceiras presentes em um retângulo de 2,0 × 18,0 m e, em seguida, o número de perfilhos de duas touceiras representativas da condição média naquele piquete e, o índice de área foliar residual (IAF), que foi realizado a partir do segundo ciclo de pastejo, com o auxílio de um quadro com chapa de vidro quadriculado $\left(4,0 \mathrm{~cm}^{2}\right)$, em que as lâminas foliares residuais eram distribuídas sob a chapa de vidro e contados o número de vértices das lâminas sobrepostas pelo quadrado, pela equação:

$$
\mathrm{IAF}_{\text {res }}=\left(\mathrm{A}_{\text {ret }} \times \mathrm{M}_{\text {amostra }}\right) / \mathrm{M}_{\text {ret }}
$$

em que $\mathrm{IAF}_{\text {res }}=$ índice de área foliar residual (adimensional); $\mathrm{A}_{\text {ret }}=$ área dos retângulos $\left(\mathrm{cm}^{2}\right) ; \mathrm{M}_{\text {amostra }}=$ massa fresca da amostra de lâminas foliares (g); $\mathrm{M}_{\text {ret }}=$ massa fresca dos retângulos (g).

Os dados foram analisados por meio de análise de variância (ANOVA), de teste de comparação de médias e análises de regressão, onde a interação entre níveis de suplementação e ciclos de pastejo foi desdobrada somente quando significativa ao nível de $10 \%$ de probabilidade. Para comparar o efeito dos tratamentos e dos ciclos, foi utilizado o teste Tukey, a 5,0\% de probabilidade. Para se estimar a resposta aos níveis de suplementação pela análise de regressão, a escolha dos modelos baseou-se na significância dos coeficientes linear e quadrático, utilizando-se o teste "t", de Student, a $10 \%$ de probabilidade. Como auxílio às análises estatísticas, utilizaram-se os procedimentos MIXED e GLM do programa estatístico SAS (SAS Institute, 1999), segundo o seguinte modelo matemático:

$$
Y i j k=\mu+T i+P(i) j+C k+(T C) i k+\varepsilon i j k
$$

em que Yijk = observação relativa ao $\mathrm{k}^{\mathrm{0}}$ piquete, no $\mathrm{j} \underline{\mathrm{o}}$ ciclo de pastejo, do i⿳⺈ nível de suplementação; $\mu$ = média da população; Ti = efeito do iơ nível de suplementação; $\mathrm{i}=1$, 2, 3, 4 níveis de suplementação; P(i)j = efeito aleatório do jo piquete do i⿳o nível de suplementação (erro a); j = 1, 2, 3 piquetes; $\mathrm{Ck}=$ efeito do $\mathrm{k}$ - ciclo de pastejo; $\mathrm{k}=1$, 2, 3, 4 ciclos de pastejo; (TC)ik = interação do ion nível de suplementação com o k $\mathrm{k}^{\underline{0}}$ ciclo de pastejo; $\varepsilon \mathrm{ijk}$ = efeito aleatório relativo ao $\mathrm{k} \underline{0}$ piquete, no $\mathrm{j} \underline{0}$ ciclo de pastejo, do iô nível de suplementação (erro b).

\section{Resultados e Discussão}

Não foi observada interação $(\mathrm{P}>0,10)$ níveis de suplementação $\times$ ciclos de pastejo para taxa de alongamento foliar (TAlF), relação entre as TAlFs das folhas $1 \mathrm{e}$ 2 (TAlF1/TAlF2), taxa de alongamento das hastes (TAlH), altura do pseudocolmo (Pseud), taxa de senescência foliar anterior (TSFa), de senescência foliar posterior (TSFp), de senescência foliar total (TST), filocrono (FIL), taxa de crescimento da cultura (TCC), taxa de acúmulo da cultura (TAC), índice de área foliar residual (IAF) e a densidade pupulacional de perfilhos (DPP). Dessa forma, os fatores foram analisados somente no efeito principal (Tabelas 2 e 3 ).

Observou-se efeito dos níveis de suplementação sobre a TAlF do pasto (Tabela 2), que, no nível de 1,8\% PV $(5,71 \mathrm{~cm} /$ perfilho $\bullet$ dia $)$, foi semelhante $(\mathrm{P}>0,05)$ àquela do nível de 1,2\% PV (5,10 cm/perfilho•dia), porém superior à dos demais (5,05 cm/perfilho•dia). Valores superiores aos obtidos neste trabalho foram relatados por Gomide \& 
Tabela 2 - Componentes do fluxo de biomassa em capim-tanzânia sob lotação rotativa com quatro níveis de suplementação concentrada

\begin{tabular}{|c|c|c|c|c|c|c|}
\hline Variável & \multicolumn{4}{|c|}{ Nível de suplementação } & CV (\%) & Equação \\
\hline TAlF (cm/perfilho•dia) & $5,02 b$ & $5,03 b$ & $5,10 \mathrm{ab}$ & $5,71 \mathrm{a}$ & 4,73 & $\hat{Y}=5,04-0,39 x+0,42 x^{2} ; R^{2}=0,64$ \\
\hline TAlF1/TAlF2 & $0,66 \mathrm{a}$ & $0,71 \mathrm{a}$ & $0,72 \mathrm{a}$ & $0,68 \mathrm{a}$ & 11,88 & $\hat{\mathrm{Y}}=0,69 \pm 0,08$ \\
\hline TAlH (cm/perfilho•dia) & $0,10 \mathrm{a}$ & $0,11 \mathrm{a}$ & $0,10 \mathrm{a}$ & $0,09 a$ & 15,39 & $\hat{\mathrm{Y}}=0,10 \pm 0,02$ \\
\hline TSFp (cm/perfilho•dia) & $0,03 a$ & $0,02 \mathrm{a}$ & $0,03 a$ & $0,03 a$ & 28,96 & $\hat{\mathrm{Y}}=0,03 \pm 0,02$ \\
\hline TST (cm/perfilho•dia) & $0,69 a$ & $0,54 \mathrm{a}$ & $0,88 \mathrm{a}$ & $0,72 \mathrm{a}$ & 24,64 & $\hat{\mathrm{Y}}=0,70 \pm 0,21$ \\
\hline FIL (dias) & $11,25 a$ & $11,47 \mathrm{a}$ & $11,67 \mathrm{a}$ & $11,60 \mathrm{a}$ & 2,75 & $\hat{\mathrm{Y}}=11,50 \pm 0,32$ \\
\hline TCC (kg MS/ha•dia) & $138,59 b$ & $207,94 a$ & $123,82 b$ & $142,77 b$ & 23,71 & $\hat{\mathrm{Y}}=153,28 \pm 36,35$ \\
\hline DPP (perf/m²) & $576 a$ & $611 \mathrm{a}$ & $544 a$ & $502 \mathrm{a}$ & 12,81 & $\hat{\mathrm{Y}}=558 \pm 71$ \\
\hline
\end{tabular}

Taxa de alongamento foliar (TAlF), relação entre as TAlFs das folhas 1 e 2 (TAlF1/TAlF2), taxa de alongamento das hastes (TAlH), altura do pseudocolmo (Pseud), taxa de senescência foliar anterior (TSFa), de senescência foliar posterior (TSFp), de senescência foliar total (TST), filocrono (FIL), taxa de crescimento da cultura (TCC), taxa de acúmulo da cultura (TAC), índice de área foliar residual (IAF) e densidade pupulacional de perfilhos (DPP).

$\mathrm{Y}=$ valores estimados a partir da equação de regressão para cada variável analisada.

Médias seguidas pela mesma letra na mesma linha não diferem $(\mathrm{P}>0,05)$, pelo teste Tukey.

Tabela 3 - Fluxo de biomassa do capim-tanzânia sob lotação rotativa com quatro níveis de suplementação

\begin{tabular}{|c|c|c|c|c|c|c|}
\hline Variável & \multicolumn{4}{|c|}{ Ciclo de pastejo } & Média & CV (\%) \\
\hline TAlF (cm/perfilho•dia) & $5,40 \mathrm{a}$ & $5,01 \mathrm{a}$ & $5,12 \mathrm{a}$ & $5,29 a$ & 5,21 & 4,84 \\
\hline TAlH (cm/perfilho•dia) & $0,09 \mathrm{~b}$ & $0,09 \mathrm{~b}$ & $0,10 \mathrm{ab}$ & $0,13 \mathrm{a}$ & 0,10 & 16,44 \\
\hline Pseud (cm) & $16,48 b$ & $18,09 b$ & $18,23 a b$ & $20,40 \mathrm{a}$ & 18,30 & 6,56 \\
\hline TSFa (cm/perfilho•dia) & $0,79 a$ & $0,59 a$ & $0,69 a$ & $0,67 a$ & 0,69 & 24,44 \\
\hline FIL (dias) & $11,64 \mathrm{a}$ & $11,53 a$ & $11,57 \mathrm{a}$ & $11,28 \mathrm{a}$ & 11,50 & 2,91 \\
\hline TCC (kg MS/ha•dia) & $159,84 \mathrm{a}$ & $157,37 a$ & $141,27 \mathrm{a}$ & $155,50 \mathrm{a}$ & 153,50 & 10,36 \\
\hline TAC (kg MS/ha•dia) & $121,07 \mathrm{a}$ & $137,53 a$ & $120,02 \mathrm{a}$ & $133,82 \mathrm{a}$ & 128,11 & 13,76 \\
\hline IAF & - & $2,27 \mathrm{a}$ & $2,35 a$ & $1,98 \mathrm{a}$ & 2,20 & 12,30 \\
\hline DPP $\left(\right.$ perf $\left./ m^{2}\right)$ & $553 a$ & $557 \mathrm{a}$ & $550 a$ & $572 \mathrm{a}$ & 558 & 13,85 \\
\hline
\end{tabular}

Taxa de alongamento foliar (TAlF), relação entre as TAlFs das folhas 1 e 2 (TAlF1/TAlF2), taxa de alongamento das hastes (TAlH), altura do pseudocolmo (Pseud), taxa de senescência foliar anterior (TSFa), de senescência foliar posterior (TSFp), de senescência foliar total (TST), filocrono (FIL), taxa de crescimento da cultura (TCC), taxa de acúmulo da cultura (TAC), índice de área foliar residual (IAF) e densidade pupulacional de perfilhos (DPP).

(-) Refere-se à variável não avaliada durante a realização do experimento.

Médias seguidas pela mesma letra na mesma linha não diferem $(P>0,05)$ pelo teste Tukey.

Gomide (2000), que, trabalhando com cultivares de Panicum maximum; e Cândido (2005) com o cultivar Mombaça e Silva (2004) com o cultivar Tanzânia, encontraram valores de 6,0 a 8,0 cm/perfilho •dia.

A equação de regressão mostrou efeito quadrático $(\mathrm{P}<0,10)$ dos níveis de suplementação sobre a TAlF do pasto, estimada em 5,04 e 5,70 cm/perfilho dia para os níveis de 0,0 e 1,8\% PV e mínimo estimado de $4,95 \mathrm{~cm} /$ perfilho•dia com suplementação de $0,46 \%$ PV (Tabela 2 ). Os valores observados, inferiores aos encontrados por Silva (2004) em ovinos em capim-tanzânia, deveram-se possivelmente ao maior peso dos ovinos no início dessa pesquisa (24,14 kg), comparativamente aos 20,0 kg dos ovinos, provocando maior pressão de pastejo sobre a gramínea ao longo do período experimental, que passou a adquirir hábito de crescimento mais prostrado, elevando o coeficiente de extinção luminosa no interior do dossel (Sugiyama et al., 1985), provocando a redução da taxa de alongamento de folhas (Chapman \& Lemaire, 1993). Além disso, problemas ligados à irrigação e à adubação nitrogenada durante o experimento podem ter contribuído para a menor TAlF. Gomide et al. (2004) relataram que 
características morfogênicas do capim-marandu sob pastejo por bovinos não foram influenciadas $(\mathrm{P}>0,05)$ por níveis crescentes de suplementação. Não foram observadas diferenças $(\mathrm{P}>0,05)$ na TAlF entre os ciclos de pastejo, com média igual a 5,21 cm/perfilho•dia (Tabela 3). Cândido (2005) também não observou diferenças entre ciclos quando trabalhou com capim-mombaça sob pastejo de lotação rotativa com três períodos de descansos.

Não houve efeito $(\mathrm{P}>0,10)$ dos níveis de suplementação e dos ciclos de pastejo sobre a razão TAlF1/TAlF2, com média de 0,69 (Tabelas 2 e 3). Essa variável pode ser um indicativo da adequação da intensidade de pastejo. Valores mais próximos de 1,0 indicam manejo mais adequado, uma vez que haveria menor mobilização de reservas durante a rebrotação, promovendo rápido alongamento foliar desde a primeira folha produzida na rebrotação. O valor da TAlF1/TAlF2 observado neste experimento foi inferior ao relatado por Silva (2004), sob período de descanso de 2,5 folhas por perfilho, com razão TAlF1/TAlF2 média de 0,85. Essa menor razão TAlF1/TAlF2 pode estar relacionada ao maior IAF residual (2,20 - Tabela 3), contra um IAF de 1,0 relatado pelo autor, propiciando maior coeficiente de extinção luminosa, o que causou condição de maior sombreamento mútuo, comprometendo o desenvolvimento do primórdio foliar ainda durante o período de pastejo, e possivelmente repercutiu em menor capacidade fotossintética e de alongamento foliar da primeira folha produzida na rebrotação.

A taxa de alongamento das hastes (TAlH) e a altura do pseudocolmo (Pseud) não foram afetadas $(\mathrm{P}>0,10)$ pelos níveis de suplementação, com médias de $0,10 \mathrm{~cm} /$ perfilho•dia e de 18,30 cm, respectivamente (Tabela 2). A TAlH e a Pseud são variáveis morfogênicas bastante importantes para a qualidade do pasto, visto que, apesar de o alongamento das hastes favorecer o aumento na produção de matéria seca, apresenta efeitos negativos na qualidade da forragem produzida e no seu aproveitamento pelo ovino em pastejo. Não foi observada diferença $(\mathrm{P}>0,05)$ na TAlH dos pastos nociclo4(0,13cm/perfilho•dia)enociclo3(0,10 cm/perfilho•dia), porém a TAlH do pasto no último ciclo foi superior $(\mathrm{P}<0,05)$ àquela dos ciclos 1 e $2(0,09 \mathrm{~cm} /$ perfilho•dia) (Tabela 3). $\mathrm{O}$ mesmo comportamento ocorreu com a variável Pseud, já que ambas são correlacionadas positivamente $\left(0,71^{* *}\right)$. Resultados semelhantes foram relatados por Cândido (2005) com capim-mombaça, que também observou elevação da TAlH no decorrer dos ciclos, mostrando a dificuldade de se manter uma estrutura favorável ao desempenho animal em dossel de gramínea cespitosa do tipo $\mathrm{C}_{4}$ ao longo de ciclos de pastejo sucessivos, visto que o alongamento das hastes é processo contínuo, progressivo e difícil de ser controlado. Além disso, a elevação das hastes compromete a estrutura do pasto pela elevação do meristema apical com a conseqüente decapitação pela desfolhação ou pelo pisoteio dos animais, comprometendo também o consumo voluntário de MS pelo animal em pastejo em decorrência do espessamento da parede celular vegetal secundária, com o acúmulo de lignina e de carboidratos estruturais menos digestíveis. Portanto, deve ser destacada a importância da adoção de práticas de manejo que visem ao seu controle.

A taxa de senescência foliar anterior (TSFa), referente às folhas que permaneceram no pasto após a desfolhação dos animais e senesceram, não foi afetada pelos níveis de suplementação $(\mathrm{P}>0,10)$ nem pelos ciclos de pastejo $(\mathrm{P}>0,05)$ e ficou com média de $0,66 \mathrm{~cm} /$ perfilho•dia (Tabela 2). Essa variável pode ser um indicativo em grande parte da intensidade de pastejo adotada, pois pastejo mais intenso repercute em menor área foliar residual e, conseqüentemente, em menor quantidade de folhas que entrarão em senescência, reduzindo a TSFa. Também pode ser um indicativo, embora que em menor proporção, de freqüência de pastejo, uma vez que períodos de descanso prolongados demais poderão ocasionar a senescência das primeiras folhas produzidas na rebrotação. Essas folhas, quando já mortas, serão rejeitadas pelo animal em pastejo e participarão da quantificação da senescência das folhas produzidas no período de descanso anterior (TSFa). O valor observado nesta pesquisa está dentro do intervalo descrito por Silva (2004), de 0,54 a 1,04 cm/perfilho•dia, para o capim-tanzânia com período de descanso variando de 17 a 27 dias, respectivamente e reflete a manutenção do pasto em condição residual adequada, acima inclusive do IAF de 1,0 preconizado por esse autor.

A taxa de senescência foliar posterior (TSFp) não foi afetada pelos níveis de suplementação $(\mathrm{P}>0,10)$ nem pelos ciclos de pastejo $(\mathrm{P}>0,05)$ e apresentou valor médio de $0,03 \mathrm{~cm} /$ perfilho $\bullet$ dia (Tabelas 2 e 3). A TSFp é indicativo do ajuste da freqüência de desfolhação à fisiologia do dossel, pois um pasto manejado para alta eficiência de uso da forragem produzida deve prevenir a senescência de folhas formadas na rebrotação, ou seja, deve apresentar TSFp igual ou próxima de zero. O valor observado neste trabalho, embora superior ao relatado por Silva (2004) é desprezível e reflete o bom ajuste do período de descanso adotado, prevenindo perdas de forragem pela senescência de novas folhas formadas. A taxa de senescência foliar total (TST) não foi afetada nem pelos níveis de suplementação ( $\mathrm{P}>0,10)$, nem pelos ciclos de pastejo ( $\mathrm{P}>0,05)$, com média igual a $0,70 \mathrm{~cm} /$ perf $x$ dia (Tabelas 2 e 3), inferior àquela verificada por Barbosa et al. (2002) em capim-tanzânia sob 
dois resíduos pós-pastejos (2,3 e 3,6 t MS/ha) equivalentes a alturas residuais de 25 e $40 \mathrm{~cm}$ respectivamente, os quais relataram TST na ordem de 1,24 e 1,33 cm/perfilho•dia. Os autores afirmaram que a TST ocorreu principalmente nas folhas remanescentes do pastejo anterior e não foi verificada nas folhas que surgiram durante os 35 dias de descanso. A menor TST observada neste trabalho é um fato inesperado, visto que a massa seca de forragem total residual (MSFT) foi de $6121 \mathrm{~kg}$ MS/ha (dados não apresentados), portanto, superior à descrita por esses autores. Dessa forma, é possível que o menor período de descanso (21 dias), aliado às melhores condições de luz, água e temperatura, tenha proporcionado menor TST.

Não houve efeito dos níveis de suplementação $(\mathrm{P}>0,10)$ nem dos ciclos de pastejo $(\mathrm{P}>0,05)$ para a variável FIL, cuja média foi de 11,5 dias (Tabelas 2 e 3). Este valor é superior aos relatados por Gomide \& Gomide (2000), de 10,6 dias, trabalhando com Panicum maximum cv. Mombaça sob corte em casa de vegetação e sem limitação hídrica e/ou nutricional e, semelhantes aos relatados por Cândido (2003), estudando o mesmo cultivar em campo. Silva (2004), trabalhando com capim-tanzânia, relatou filocrono médio de 12,9 dias, com período de descanso equivalente a 1,81 folhas por perfilho.

Não foram observadas diferenças $(\mathrm{P}>0,05)$ na taxa de crescimento da cultura (TCC) dos níveis de suplementação de 0,0; 1,2 e 1,8\% PV, com média de 135,06 kg MS/ha•dia, a qual foi inferior $(\mathrm{P}<0,05)$ à do pasto cujos ovinos receberam 0,6\% de suplementação, com média de 207,94 kg MS/ha•dia (Tabela 2). O mesmo ocorreu com a variável taxa de acúmulo da cultura (TAC), mostrando que ambas são correlacionadas positivamente $(0,97 * *)$.

Não foram observados efeitos $(\mathrm{P}>0,10)$ nem dos níveis de suplementação nem dos ciclos de pastejo $(\mathrm{P}>0,05)$ sobre a TCC e a TAC, que apresentaram valores médios de 153,28 e 128,70 kg MS/ha•dia, respectivamente (Tabelas 2 e 3), superiores às obtidas por Silva (2004), no mesmo cultivar, o qual relatou TCC e TAC de 108,29 e 99,87 kg MS/ha•dia, com período de descanso equivalente a 1,81 folha por perfilho. Considerando que esse autor trabalhou com IAF residual de 1,0, contra um IAF residual de 2,20 neste trabalho, a maior TCC deste estudo pode estar relacionada à maior fotossíntese bruta do dossel, variável influenciada diretamente pelo IAF e repercute na taxa de crescimento da cultura (Zelitch, 1982). O acúmulo de forragem é o resultado do balanço entre os componentes do fluxo de biomassa individualmente e ao nível de comunidade. A pequena diferença entre a TCC e a TAC reflete o controle do processo de senescência, o que pode ser comprovado pela TSFp que foi desprezível (Tabela 2). Por outro lado, a diferença entre a TCC e a TAC pode ser atribuída à massa de forragem residual, que foi bastante elevada, uma vez que o capim adquiriu hábito de crescimento mais prostrado em resposta ao pastejo intenso. Sugiyama et al. (1985) relataram que plantas de crescimento mais prostrado apresentam maior coeficiente de extinção, o que acelera o processo de sombreamento mútuo que, por sua vez, acelera a senescência das folhas verdes (Hunt et al., 1965). Os valores de TAC situaram-se entre 93,21 e 189,14 kg MS/ha•dia, comprovando o grande potencial de produção dessa cultivar, dentro dos valores apresentados por Cândido (2005) para o cultivar Mombaça com três períodos de descansos, cuja TAC variou entre 93 e $202 \mathrm{~kg} \mathrm{MS/ha•dia.}$

Quanto ao efeito dos níveis de suplementação sobre o índice de área foliar residual (IAF) (Tabela 2), o pasto dos ovinos com suplementação no nível de 1,8\% PV $(2,70)$ foi semelhante $(\mathrm{P}>0,05)$ àquele em que os ovinos receberam suplemento no nível de 1,2\% PV (2,23), porém superior $(\mathrm{P}<0,05)$ aos demais.

O estudo da equação de regressão mostrou efeito quadrático $(\mathrm{P}<0,10)$ dos níveis crescentes de suplementação sobre o IAF do pasto (Tabela 2). Estimou-se IAF residual de 2,00 e 2,72 nos pastos em que os ovinos receberam suplemento nos níveis de 0,0 e 1,8\% PV, respectivamente, e mínimo estimado de 1,89 com $0,52 \%$ de suplementação. Não foram observadas diferenças $(\mathrm{P}>0,05)$ entre ciclos para a variável IAF, cuja média foi de 2,20 (Tabela 3). Embora não tenha havido diferença no IAF entre os ciclos, a tendência de redução no mesmo do terceiro para o quarto ciclo reforça o risco de se manejar o pasto com base na sua altura. A elevação na taxa de alongamento das hastes (TAlH) (Tabela 3) do segundo para o quarto ciclo fez com que, para uma mesma altura de resíduo pós-pastejo, restasse menor área foliar em um pasto que teve suas hastes alongadas (principalmente no último ciclo), elevando o dossel e aumentando a proporção de folhas removidas durante o pastejo.

Em termos absolutos, o maior IAF nos pastos cujos ovinos receberam 1,2 e 1,8\% de suplementação, especialmente neste último, são um indicativo de ocorrência de efeito substitutivo do suplemento, pelo menos no maior nível de suplementação. Dessa forma, o IAF residual tem um papel fundamental na rebrotação do pasto, pois a área foliar verde remanescente após o pastejo é diretamente proporcional à taxa de fotossíntese líquida do pasto (Gomide et al., 2002). Além disso, quanto maior a proporção de lâminas foliares remanescentes, menor a necessidade da planta em mobilizar suas reservas orgânicas para retomar seu crescimento. 
Quanto à densidade populacional de perfilhos (DPP), não foi observada diferença entre níveis de suplementação nem entre ciclos de pastejo $(\mathrm{P}>0,10)$, ficando com média igual a 558 perfilhos $/ \mathrm{m}^{2}$ (Tabelas 2 e 3). Apesar da possibilidade de o nível de suplementação de 1,8\% PV comprometer a estrutura da pastagem, pelo maior número de animais e pelo seu maior peso, não se observaram indícios de degradação, uma vez que a DPP não foi alterada $(\mathrm{P}>0,05)$ com os níveis de suplementação e foi superior àquela relatada por Silva (2004) para o mesmo cultivar sob três períodos de descanso (1,5; 2,5 e 3,5 folhas por perfilho), que obteve DPP de 431; 472 e 378 perfilhos $/ \mathrm{m}^{2}$, respectivamente. Este resultado não era esperado, visto que neste experimento o IAF residual médio de 2,20 foi maior que o desse autor $(1,0)$, conferindo melhor condição de rebrotação e podendo chegar mais rapidamente aos IAFs que desencadeasse sombreamento mútuo, inibindo o perfilhamento. Infere-se que o hábito de crescimento mais prostrado refletiu maior IAF para a mesma altura residual do pasto adotada $(28,0 \mathrm{~cm})$, inibindo possivelmente a brotação de novas gemas. Por outro lado, é possível que tenha havido compensação com a quebra da dominância apical de muitos perfilhos decapitados por ocasião da maior intensidade de pastejo aqui observada, estimulando a brotação de gemas basilares e axilares e, conseqüentemente, o perfilhamento. Costa et al. (1992), trabalhando no interior de São Paulo com os cultivares Colonião e Tobiatã, relataram DPP de 526 e 394 perfilhos $/ \mathrm{m}^{2}$, respectivamente. Canto et al. (2002), por sua vez, trabalhando com diferentes alturas de capim-tanzânia no Noroeste do Paraná, citaram DPP de 625 perfilhos $/ \mathrm{m}^{2}$ quando submetida a cortes de 55,8 $\mathrm{cm}$. Apesar de as condições climáticas deste experimento terem sido ideais para a obtenção de elevadas produtividades, as elevadas DPP relatadas por esses autores deveu-se principalmente às elevadas doses de nitrogênio aplicadas (média de $50 \mathrm{~kg} \mathrm{~N} / \mathrm{ha} \bullet$ ciclo), enquanto neste experimento a dose nitrogenada aplicada foi de 39,6 kg/ha•ciclo.

\section{Conclusões}

Os componentes do fluxo de biomassa do capim-tanzânia são pouco afetados pelos níveis de suplementação, que têm maior influência sobre a taxa de alongamento foliar, a taxa de crescimento da cultura, a taxa de acúmulo da cultura e o índice de área foliar residual. Apesar da redução no acúmulo de forragem nos mais altos níveis de suplementação, os índices morfogênicos se mantêm nos patamares aceitáveis com a persistência da pastagem mesmo no mais alto nível de suplemento. Considerando de modo geral essas variáveis, há equilíbrio entre os processos de produção e utilização de forragem em todos os níveis estudados, porém estudos adicionais devem ser feitos considerando a resposta dos animais em pastejo.

\section{Literatura Citada}

ALEXANDRINO, E.; GOMIDE, C.A.M.; CÂNDIDO, M.J.D. et al. Período de descanso, características estruturais do dossel e ganho de peso vivo de novilhos em pastagem de capim-Mombaça sob lotação intermitente. Revista Brasileira de Zootecnia, v.34, n. 6, p.2174-2184, 2005 (supl.).

BARBOSA, R.A.; NASCIMENTO JR., D.; EUCLIDES, V.P.B. et al. Características morfogênicas e acúmulo de forragem do capim Tanzânia (Panicum maximum Jacq. cv. Tanzânia) em dois resíduos forrageiros pós-pastejo. Revista Brasileira de Zootecnia, v.31, n.2, p.583-593, 2002.

CÂNDIDO, M.J.D. Morfofisiologia e crescimento do dossel e desempenho animal em Panicum maximum cv. Mombaça sob lotação intermitente com três períodos de descanso. 2003. 134f. Tese (Doutorado em Zootecnia) - Universidade Federal de Viçosa, Viçosa, MG, 2003.

CÂNDIDO, M.J.D.; GOMIDE, C.A.M.; ALEXANDRINO, E. et al. Morfofisiologia do dossel de Panicum maximum cv. Mombaça sob lotação intermitente com três períodos de descanso. Revista Brasileira de Zootecnia, v.34, n.2, p.338-347, 2005.

CANTO, M.W.; CECATO, U.; ALMEIDA JR., J. et al. Produção animal no inverno em capim Tanzânia diferido no outono e manejado em diferentes alturas de pasto. Revista Brasileira de Zootecnia, v.31, n.4, p.1624-1633, 2002.

CHAPMAN, D.F.; LEMAIRE, G. Morphogenetic and structural determinants of plant regrowth after defoliation. In: BAKER, M.J. (Ed.). Grassland for our world. Wellington: SIR Publishing, 1993. p.55-64.

COMISSÃO DE FERTILIDADE DO SOLO DO ESTADO DE MINAS GERAIS - CFSEME. Recomendações para uso de corretivos e fertilizantes em Minas Gerais - $5^{\text {a }}$ aproximação. Viçosa, MG: Universidade Federal de Viçosa, 1999. 359p.

COSTA, C.; FAVORETTO, V.; MALHEIROS, E.B. Estudo da variação na estrutura da vegetação de duas cultivares de Panicum maximum Jacq. (Colonião e Tobiatã) submetidas a diferentes tipos de manejo. Pesquisa Agropecuária Brasileira, v.27, n.1, p.131-142, 1992.

DAVIES, A. Tissue turnover in the swards. In: DAVIES, A.; BAKER, R.D.; GRANT, S.A. et al. (Eds.). Swards measurement handbook. 2.ed. Reading: British Grassland Society, 1993. p.183-216.

EMPRESA BRASILEIRA DE PESQUISA AGROPECUÁRIA EMBRAPA. Sistema brasileiro de classificação dos solos. Brasília: Embrapa CNPS, 1999. 412p.

GOMIDE, C.A.M. Características morfofisiológicas associadas ao manejo do capim Mombaça (Panicum maximum Jacq.). 2001. 109f. Tese (Doutorado em Zootecnia) - Universidade Federal de Viçosa, Viçosa, MG, 2001.

GOMIDE, J.A.; GOMIDE, C.A.M. Morfogênese de cultivares de Panicum maximum Jacq. Revista Brasileira de Zootecnia, v.29, n. 2, p.341-348, 2000.

GOMIDE, C.A.M.; GOMIDE, J.A.; HUAMAN, C.A.M. et al Fotossíntese, reservas orgânicas e rebrota do capim-mombaça (Panicum maximum Jacq.) sob diferentes intensidades de desfolha do perfilho principal. Revista Brasileira de Zootecnia, v.31, n.6, p.2165-2175, 2002.

GOMIDE, C.A.M.; REIS, R.A.; FREITAS, D. Estrutura da pastagem de capim Marandu sob pastejo de lotação intermitente, em resposta a níveis de suplementação alimentar de novilhos. In: REUNIÃO ANUAL DA SOCIEDADE BRASILEIRA DE ZOOTECNIA, 41., 2004, Campo Grande. Anais... Campo Grande: Sociedade Brasileira de Zootecnia, 2004. (CD-ROM). 
HUNT, L.A. Some implications of death and decay in pasture production. Journal of the British Grassland Society, v.20, n.1, p.27-31, 1965.

NABINGER. C.; PONTES, L.S. Morfogênese de plantas forrageiras e estrutura do pasto. In: REUNIÃO ANUAL DA SOCIEDADE BRASILEIRA DE ZOOTECNIA, 38., 2001, Piracicaba. Anais... Piracicaba: Sociedade Brasileira de Zootecnia, 2001. p.755-771.

STATISTICAL ANALYSIS SYSTEM - SAS. SAS system for windows. Version 8.0. Cary: SAS Institute, 1999. (CD-ROM).

SILVA, R.G. Morfofisiologia do dossel e desempenho produtivo de ovinos em Panicum maximum (Jacq.) cv. Tanzânia sob três períodos de descanso. 2004. 114f. Dissertação (Mestrado em Zootecnia) - Universidade Federal do Ceará, Fortaleza, 2004. SKINNER, R.H.; NELSON, C.J. Elongation of the grass leaf and its relationship to the phyllochron. Crop Science, v.35, n.1, p.4-10, 1995.

SUGIYAMA, S.; YONEYAMA, M.; TAKAHASHI, N. et al. Canopy structure and productivity of Festuca arundinaceae Schreb, swards during vegetative and reproductive growth. Grass and Forage Science, v.40, n.1, p.49-55, 1985.

ZELITCH, I. The close relationship between net photosynthesis and crop yield. Bioscience, v.32, p.796-802, 1982 